ARTICLE

\title{
On the probability ratio index as a measure of electoral competition
}

\author{
Satya R. Chakravarty ${ }^{1}$, Manipushpak Mitra ${ }^{1 凶}$, Suresh Mutuswami ${ }^{2}$ \& Rupayan Pal (i] ${ }^{3}$
}

\begin{abstract}
This paper deals with the fundamental issue of quantifying the degree of competitiveness underlying an election in a society. That is, given the vote shares of competing political parties in the election one needs to arrive at a representative metric of electoral competition. The vote share of a party represents its influence on the outcome of the election. A summary measure of differences of such influences across parties, aggregated in an unambiguous way, is an index of electoral competitiveness. The literature contains several such indices. Implicit under the choice of an index is a set of properties that the index satisfies. A highly attractive feature of the probability ratio index we suggest in this article, as a summary measure of electoral competition, is its suitability for making comparisons of competitiveness across elections with different number of parties. The probability ratio index is simply the ratio between the probabilities that the two voters drawn at random with (without) replacement have voted for different parties under actual vote shares across the competing parties and under equal vote shares across them. The comparability feature of the probability ratio index can be maintained without sacrificing any nice characteristic expected from an electoral competition measure. The probability ratio index is inversely related to the well-known Herfindahl-Hirschman concentration index that indicates dominance of large parties, directly related to the fractionalization index, which indicates how vote shares are split among the parties, and also inversely related to the squared coefficient of variation, a highly popular measure of inequality. It is argued explicitly how the new index can be applied to measure competitiveness for true data. Simple examples are used to demonstrate why probability ratio index has a comparative advantage over some other well-known indices, particularly, in terms of cross-election comparability.
\end{abstract}

\footnotetext{
${ }^{1}$ Economic Research Unit, Indian Statistical Institute, Kolkata, India. ${ }^{2}$ Economics Division, School of Business, University of Leicester, Leicester, UK.

${ }^{3}$ Indira Gandhi Institute of Development Research, Mumbai, India. ${ }^{凶}$ email: mmitra@isical.ac.in
} 


\section{Introduction}

- he mechanism of representation of political parties is fundamental in a democratic system and the degree of electoral competition among political parties in elections is an important aspect of this mechanism. By electoral competition, we mean the result of interactions between voters and vote seekers in a systemic way (Giebler et al., 2017). The importance of electoral competition was highlighted, among others, by Dahl (1971). The presence of electoral competition is claimed to improve representation (Powell, 2000), increase voter turnout (Franklin, 2004), improve economic performance (Przeworski and Limongi, 1993), enhance the quality of governance (Hobolt and Klemmensen, 2008), and, in new democracies, induce stability (Wright, 2008). Electoral competition is likely to keep the parties motivated to work for increasing the well-being of the society in order to get voters' support. Parties may select good candidates and reallocate resources to pivotal constituencies where anti-incumbent factors are likely to affect voters' decisions. Such investments may take the form of investments in local public goods, for instance, mass inoculation program in the area etc. In contrast, other studies claim that political competition has both good and bad effects on adopted policies, policy outcomes, and economic growth (Acemoglu and Robinson, 2006; Bardhan and Yang, 2004; Besley, 2006; Besley and Ghatak, 2005; Lizzeri and Persico, 2005; Persson et al., 1997). Some studies find no effect or highlight the disruptive nature of too much political competition (see, for example, Powell, 1982). Moreover, authors like Duverger (1964) and Boix (1999) argue that electoral competition can itself be influenced by a wide array of factors. For example, a recent study by Afridi et al. (2019) indicated that responsiveness of corruption to Indian electoral competition is of mixed type. According to their findings, the only type of corruption that is sensitive to electoral competition is one in which voters lose private benefits. In contrast, corruption in public goods was not found to be receptive.

Thus, the level of competition in contemporary political systems and its consequences are still a matter of debate; in part, it also reflects a lack of conceptual clarity (Bischoff, 2006). Still, one cannot deny the importance of electoral competition in a democracy and hence, a measure of competition calls for an indepth theoretical analysis. In this paper, we ask this basic question: how should we measure the degree of electoral competitiveness? Specifically, suppose we have the vote shares of competing political parties in an election. Using this data, how do we obtain a representative measure of electoral competition?

The use of vote shares is a limitation because the degree of electoral competition is affected by many factors, not all of which are reflected in the vote shares of parties. To the extent that factors affecting electoral competition are not reflected in the vote shares of parties, our measure will give a misleading picture. Unfortunately, these factors are often particular to a constituency, state or country, and changes over time. Consideration of such factors-even when data on them are publicly available-raises the tricky problem of how to incorporate them into the index in a consistent manner, particularly when we do cross-country or cross-constituency and/or time series analysis. On the other hand, data on vote shares are available for nearly all democracies. Since our interest is in developing an index, which can be used for comparisons, we focus on vote shares, even while recognizing its limitations.

Some measures from the existing literature. The literature on electoral competitiveness is too large to survey here; hence, we are constrained to be selective in our discussion of electoral competition measures. To quote Kayser and Lindstädt (2015): "In a recent 5-year period, approximately every other issue of the
American Political Science Review, American Journal of Political Science, and Journal of Politics published an article related to electoral competitiveness." Mayhew (1974) employed the winning margin (the percentage vote difference between the two largest parties) as a measure of competition. Recently, the winning margin was used by Dash and Mukherjee (2015) to understand the relation between political competition and human development and by Mitra and Mitra (2017) to understand the link between electoral uncertainty and income inequality. Vanhanen (1997), in a similar vein, used the share of the votes won by the most popular candidate. These measures are meaningful provided there are only two competing parties. In multi-party elections, these measures suffer from the shortcoming that they ignore the other candidates and the distribution of votes among the candidates. A suitable electoral competitiveness measure must be able to work in multi-party elections because several countries have such systems. More importantly, in most of these countries the number of candidates varies widely over time and across constituencies. For instance, the number of candidates in the 2002 German elections varied from 3 to 10; in contrast, it varied from 6 to 16 in 2013. In Argentina, the number of candidates varied from 4 to 22 in 2001 and from 2 to 7 in 2015.

The vote share of a party represents its influence on outcome of an election. Competitiveness means a scalar representation of differences of such influences across parties. There are many possible representations, each of which satisfies different properties. The index that one chooses thus depends on the set of properties that one wants the index to satisfy. In our case, we require that not only should the distribution of vote shares matter but also that the measure must be such that one can reasonably make comparisons of competitiveness across elections with different number of parties. The need for comparability of the electoral measure of concentration was felt by Alfano and Baraldi (2015) while analyzing data from the Italian regional elections. Thus, we need a measure that depends on some standard averaging principle. The oft-used Laakso-Taagepera index (hereafter, LT-index; Laakso and Taagepera, 1979), defined as the reciprocal of the sum of square of the vote shares of all the parties competing in an election, was used by Chhibber et al. (2014) to analyze political competition and party proliferation. However, with the LT-index comparison across elections is not possible since it takes values in the interval $[1, n]$, where $n$ is the number of parties. This is an undesirable feature for a competitiveness measure. The fractionalization index (Capron and Kruseman, 1988) relies on the number of votes polled for each candidate and the total number of votes polled. Dependence of this index on the total number of votes polled, as well as on the number of competing parties does not make it suitable for cross-election comparisons. The entropy index, is defined as $E_{N}(s)=-\sum_{i \in N} s_{i} l n s_{i}$, where $N=\{1, \ldots, n\}$ represents the set of parties competing in an election and $s_{i}$ represents the resulting vote share of any party $i \in N$ and, for any share $s_{i}, \ln s_{i}$ is the natural $\log$ of $s_{i}$. The entropy index, used by Kirchgassner and Schimmelpfennig (1992) and Kirchgassner and zu Himmern (1997), suffers from the same shortcomings as the LT-index because its range is $[0, \ln n]$. An index similar to the entropy index was proposed by Endersby et al. (2002), which we call the product index. This index is not suitable because it unambiguously takes on the value zero if the vote share of one or more parties is zero.

What properties should a measure of electoral competitiveness satisfy? If we are to use the measure to compare across elections with different candidate numbers, then it must be independent of 
the number of candidates. In this paper, we assume that the measure takes values in the interval $[0,1]$ where the extreme values correspond, respectively, to no competition (one party has all the votes) and "full" competition (all parties have the same share of votes). For computational ease, we also want the measure to be a "smooth" function of the vote shares (twice differentiable). This helps us in concentrating on measures that are simple. As with inequality or concentration measures (Bourguignon, 1979; Chakravarty and Eichorn, 1991; Chakravarty and Weymark, 1988; Foster, 1983; Sen, 1974), the challenge lies in developing a measure that meaningfully describes degree of competitiveness that fall between the two extremes. To cope with this challenge we require our measure to be decomposable in the sense that the index with $n$ competing parties can be represented as a weighted sum of rivalry between each party with the remaining number of parties where the weights are used for making our measure comparable across elections with different number of competing parties.

The probability ratio index. Our measure of electoral competition is based on the probability that two voters drawn at random (with replacement) belong to different parties. The idea is that the more competitive the election, the more likely two random voters will belong to different parties. This probability, therefore, gives a good measure of electoral competitiveness. Note that this probability is zero in the extreme case where one party has all the votes. In the other extreme case where all parties have the same share of votes, this probability is $(n-1) / n$ (where $n$ is the number of parties). In order to get the index to lie in the interval $[0,1]$-as well as to make the index independent of the number of partieswe normalize by dividing by $(n-1) / n$. We call this measure the probability ratio index. Our measure enables comparison of electoral competitiveness across elections with different number of parties. Moreover, in order to capture this comparability feature, we do not sacrifice any nice feature expected from a electoral competition measure because the probability ratio index is inversely related to the well-known Herfindahl-Hirschman index, directly related to the fractionalization index and also inversely related to the squared coefficient of variation, a highly popular measure of inequality. This as well justifies the use of the index for measuring competitiveness for true data.

\section{The framework}

Let $\mathcal{N}^{0}=\{1,2, \ldots\}$ be the set of potential parties and $\mathcal{N}=\left\{N \subset \mathcal{N}^{0}|2 \leq| N \mid<\infty\right\}$, where $|N|$ denotes the cardinality of the set $N$. For each $N \in \mathcal{N}$, let $\Delta(N)=\left\{s \in \mathbb{R}^{N} \mid s_{i} \geq 0\right.$ for all $i \in$ $N$ and $\left.\sum_{i \in N} s_{i}=1\right\}$ denote the simplex on $N$. An election is a tuple $\mathcal{E}=(N, s)$, where $N \in \mathcal{N}$ is the set of competing parties and $s \in \Delta(N)$ is the vote share vector. We denote by $r(s)$ the permutation of $s$ such that $r_{1}(s) \geq \ldots \geq r_{|N|}(s)$. The set of vote share vectors such that $t$ parties have an equal share of the vote and the remaining parties nothing is denoted $S(N, t)$. Hence, $S(N, t)=\left\{s \in \Delta(N) \mid r_{i}(s)=1 / t\right.$ for $\left.i \leq t\right\}$. Note that the set $s(N, \mid$ $N \mid)$ is a singleton; in what follows, we denote this singleton element as $s^{*}(N)$. Let $N \in \mathcal{N}$. A competitiveness function is a mapping $g_{N}: \Delta(N) \rightarrow[0,1]$ such that $(1) g_{N}(s)=1$ if and only if $s=s^{*}$ $(N),(2) g_{N}(s)=0$ if and only if $s \in S(N, 1)$, and, (3) $g_{N}$ is twice differentiable. The first condition says that electoral competition is highest if and only if all parties have an equal share of the vote. The second condition says that the competition is lowest if and only if one party gets all the votes. These two postulates can be regarded as normalization conditions. Each of them is a cardinality property-evidently, we can re-normalize the measure by taking some suitable affine transformation. The last condition is a smoothness requirement on the competitiveness function. A collection of competitiveness functions $G=\left\{g_{N}\right\}_{N \in \mathcal{N}}$ is a competitiveness map.

\section{The probability ratio index}

Let $N \in \mathcal{N}$ and let $s \in \Delta(N)$. Then, $\mathbb{P}_{N}^{2}(s):=1-\sum_{i \in N} s_{i}^{2}$ denotes the probability that two voters drawn at random (with replacement) have voted for two different parties. The GiniSimpson index of diversity is exactly this probability (Gini, 1912; Simpson, 1949), where a diversity index is a quantitative measure that reflects how many different types of objects are present in a dataset, and simultaneously takes into account how evenly the basic entities are distributed among those types (Jost, 2006). Note that $\mathbb{P}_{N}^{2}(s)$ attains its minimum value of zero when $s \in S(N, 1)$ and its maximum value of $(|N|-1) /|N|$ when $s=s^{*}(N)$. The probability ratio index is proportional to the Gini-Simpson index where the proportionality factor is the reciprocal of $\mathbb{P}_{N}^{2}\left(s^{*}(N)\right)$.

A competitiveness map $G^{*}$ is the probability ratio index if for any $N \in \mathcal{N}, g_{N}^{*}(s):=\frac{\mathbb{P}_{N}^{2}(s)}{\mathbb{P}_{N}^{2}\left(s^{*}(N)\right)}=\frac{|N|}{|N|-1}\left[1-\sum_{i=1}^{n} s_{i}^{2}\right]$.

The probability ratio index is well-defined since $g_{N}^{*}(s)=0$ for $s$ $\in S(N, 1), g_{N}^{*}(s)=1$ for $s=s^{*}(N)$ and $g_{N}^{*}(s) \in(0,1)$ for $s \in \Delta(N) \backslash\left\{S(N, 1) \cup s^{*}(N)\right\}$. It is also obvious that derivatives of all orders exist.

We define a rivalry function $B^{*}($.) that represents electoral contest between a party with vote share $s_{i}$ and a second party with vote share $\left(1-s_{i}\right)$. Suppose there are two parties $N=\{1$, $2\}$ competing in an election. In this case, the competitiveness function associated with the probability ratio index is this rivalry function $B^{*}(x):=g_{N}^{*}(x, 1-x)=2\left\{1-x^{2}-(1-\right.$ $\left.x)^{2}\right\}=4 x(1-x)$ and is defined for all $x \in[0,1]$. Hence, the competitiveness function $B^{*}(x)$ is a parabola symmetric around $x=1 / 2$, as shown in Fig. 1. Similarly, suppose there are three parties $N=\{1,2,3\}$ competing in an election. In this case, the competitiveness function associated with the probability ratio index is given by $g_{N}^{*}(x, y, z)=(3 / 2)\left\{1-x^{2}-y^{2}-z^{2}\right\}$

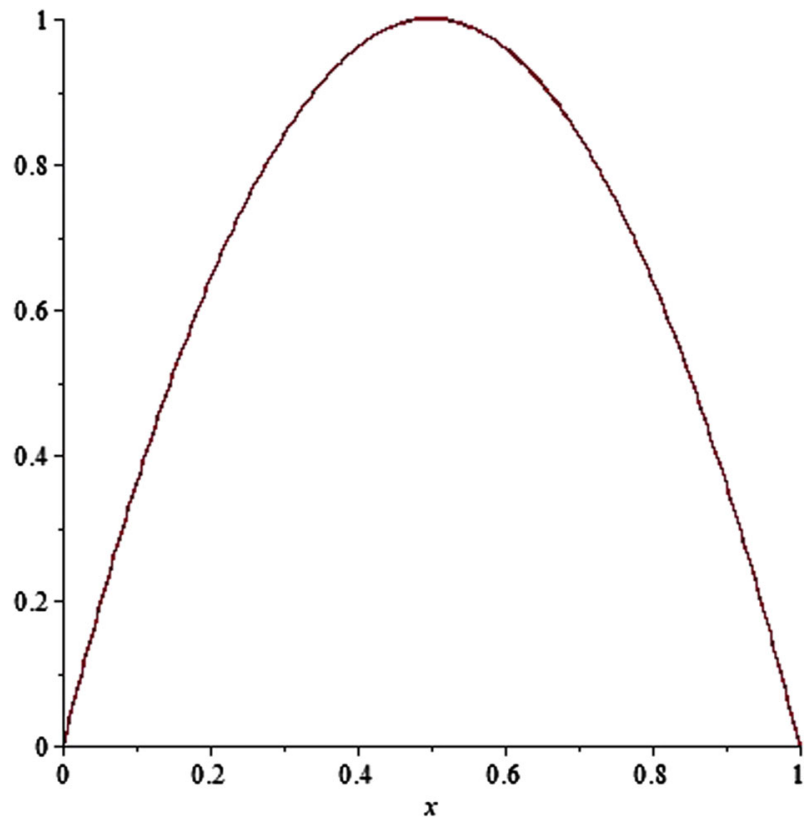

Fig. 1 The probability ratio index with two parties. The function $B^{\star}(x)=4 x$ $(1-x)$ for all $(x, 1-x) \in \Delta(N)$. 


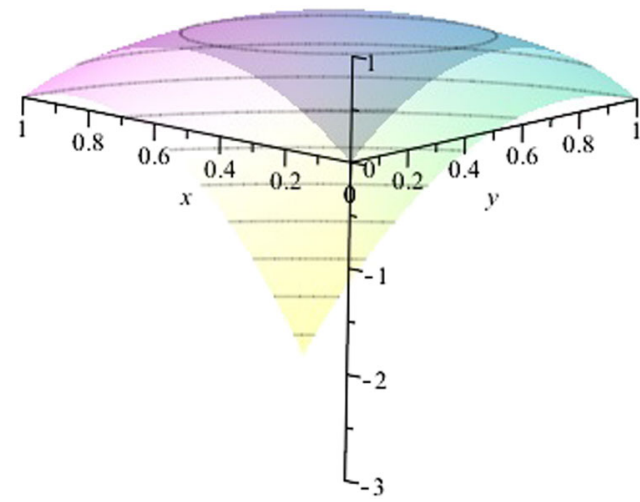

Fig. 2 The probability ratio index with three parties. The function $g_{N}^{*}(x, y$, $1-x-y)=(3 / 8)\left\{B^{*}(x)+B^{*}(y)+B^{*}(1-x-y)\right\}$ for all $(x, y, 1-x-y) \in \Delta(N)$.

$=(3 / 2)\{x(1-x)+y(1-y)+z(1-z)\}=(3 / 8)\left\{B^{*}(x)+B^{*}\right.$

$\left.(y)+B^{*}(z)\right\}$ for all $(x, y, z) \in \Delta(N)$, given $N=\{1,2,3\}$. Figure 2 is a plot of the function $g_{N}^{*}(x, y, 1-x-$ $y$ ) for all $(x, y, 1-x-y) \in \Delta(N)$, given $N=\{1,2,3\}$. In general, for any finite set of political parties $N$ with $|N| \geq 2$ and with any vote share vector $s=\left(s_{1}, \ldots, s_{N}\right) \in \Delta(N)$, we have

$$
g_{N}^{*}(s)=\frac{|N|}{|N|-1} \sum_{i \in N} B^{*}\left(s_{i}\right) .
$$

This decomposability formula indicates that our probability ratio metric can be expressed as a normalized sum of all possible rivalry functions that may arise in the context. This decomposability is an important and attractive feature of our index. Also note that the probability ratio index does not depend on characteristics other than vote shares. To be more specific, if $s$ and $s^{\prime}$ are vote share vectors such that $s^{\prime}$ is a permutation of $s$, then $g_{N}^{*}(s)=g_{N}^{*}(s /)$, that is, the probability ratio index satisfies vote share anonymity.

\section{Comparisons with some alternatives and variants}

Generalized probability ratio indices. We can generalize the probability ratio index as follows:

$$
\forall N \in \mathcal{N}, \forall s \in \Delta(N): \quad Q_{N}^{k(N)}(s)=\frac{\mathbb{P}_{N}^{k(N)}(s)}{\mathbb{P}_{N}^{k(N)}\left(s^{*}(N)\right)}
$$

where $k(N) \geq 2$ is the number of voters drawn at random with replacement when the set of competing parties is $N$. It can be checked that such indices will always take values in $[0,1]$. Observe that for the probability ratio index, $k(N)=2$ for all $N$. There is also the product index defined as $C_{N}(s)=|N|^{|N|} \Pi_{i \in N} s_{i}$, which is obtained by setting $k(N)=|N|$ for all $N$. However, if $k$ $(N)>2$ for some $N$, then we will not have a competitiveness map because the index can take the value zero even when two or more parties have strictly positive vote shares. For instance, suppose $N=\{1,2,3, \ldots, n\}$ and consider $s$ such that $s_{1}=s_{2}=1 / 2$ and $s_{i}=$ $0,3 \leq i \leq n$. Then $P_{N}^{k(N)}(s)=0$ for all $k(N) \geq 3$ meaning that $Q_{N}^{k(N)}(s)=0$ but this violates the definition of the competitiveness function: recall that the competitiveness index takes the value zero if and only if one party has the entire vote share. Therefore, a generalized probability ratio is a competitiveness map if and only if it is the probability ratio index.

Relationship with measures of concentration. The probability ratio index is closely related to the $\mathrm{HH}$-index (henceforth, $\mathrm{HH}$ index), defined as $H H_{N}(s)=\sum_{i \in N} s_{i}^{2} \quad$ (Herfindahl, 1950; Hirschman, 1964). An easy computation shows that
$g_{N}^{*}(s)=\left(1-H H_{N}(s)\right) / \mathbb{P}_{N}^{2}\left(s^{*}(N)\right)$. Thus, the probability ratio index has a negative monotone relationship with the $\mathrm{HH}$-index. The same relationship also holds with the normalized $\mathrm{HH}$-index of electoral concentration defined as $\overline{H H}_{N}(s)=(|N| /(|N|-$ 1)) $\left[H_{N}(s)-(1 /|N|)\right]$ (Alfano and Baraldi, 2015); indeed, $g_{N}^{*}(s)=1-\overline{H H}_{N}(s)$. The negative monotonic transformation of $\overline{H H}_{N}(s)$, which is not a measure of electoral competition, enables the resulting measure to be an appropriate measure of electoral competition.

Relationship with the coefficient of variation. The coefficient of variation of a vote share vector $s$, denoted $C V_{N}(s)$ is defined as the ratio of the standard deviation to the mean. The maximum coefficient of variation is attained when any one party has the entire vote share: $\overline{C V}_{N}:=\sqrt{|N|-1}$. One can easily verify that $g_{N}^{*}(s)=1-\left\{C V_{N}(s) / \overline{C V}_{N}\right\}^{2}$. Therefore, $g_{N}^{*}(s) \gtreqless g_{N}^{*}(s \prime)$ if and only if $C V_{N}(s) \lesseqgtr C V_{N}(s /)$. Thus, there is a negative monotonic relation between the probability ratio index and the coefficient of variation. Interestingly, it also follows that

$$
\overline{H H}_{N}(s)=\left[\frac{C V_{N}(s)}{\overline{C V}_{N}}\right]^{2}=1-g_{N}^{*}(s) .
$$

Hence, the normalized $\mathrm{HH}$-index is the square of the ratio between actual covariance and maximum covariance.

With and without replacement. Let $\mathbf{v}=\left(v_{i}\right)_{i \in N}$ be the vector of votes polled by the candidates and let $V=\sum_{i=1}^{n} v_{i}$. Capron and Kruseman (1988) proposed the fractionalization index $\mathcal{F}_{N}(\mathbf{v} ; V)=1-\sum_{i=1}^{n}\left[\left(v_{i} / V\right)\left(\left(v_{i}-1\right) /(V-1)\right)\right] V$. Defining $s_{i}$ $=v_{i} / V$, we can rewrite this index in terms of vote shares and the total votes polled: $\mathcal{F}_{N}(s ; V)=(V /(V-1))\left[1-\sum_{i \in N} s_{i}^{2}\right]$.

Let $\tilde{\mathbb{P}}_{N}^{2}$ denote the probability that two voters drawn at random without replacement have voted for different parties. It is easy to show that $\mathcal{F}_{N}(s ; V)=\tilde{\mathbb{P}}_{N}^{2}(s)=(V /(V-1)) \mathbb{P}_{N}^{2}(s)$. The normalized fractionalization index is defined as

$$
F_{N}^{*}(s)=\frac{\mathcal{F}_{N}(s ; V)}{\mathcal{F}_{N}\left(s^{*}(N) ; V\right)}=\frac{|N|}{|N|-1}\left[1-\sum_{i \in N} s_{i}^{2}\right]=g_{N}^{*}(s) .
$$

Hence, the probability ratio index can also be interpreted as the ratio between the probabilities that two voters drawn at random without replacement have voted for different parties under actual vote shares across the competing parties and under equal vote shares across them.

Political heterogeneity. Capron and Kruseman (1988) proposed the fractionalization index to assess the intensity of rivalry among parties. As shown in Eq. (1), the probability ratio index can also be used as a measure of political heterogeneity. Hence, the probability ratio index as a measure of political heterogeneity can, through the election results, make the candidates more conscious about the existing social norms since fragmented voters' judgments can also be thought of as a judgment on electoral manifestos of the candidates.

Relations with some existing indices. While the Herfindahl-Hirschman index is an indicator of dominance of parties with large vote shares, the fractionalization index is a scalar representation of how distinct the parties are with respect to vote shares. However, they both remain unchanged if one or more parties with zero vote share join or leave the election scenario. In contrast, the probability ratio index recognizes the existence of such parties because it is a yardstick of vote share competitiveness. Next, let us consider two elections scenarios where the number of parties is different. If in each election the 
representative parties share vote equally, then the value of the Herfindahl-Hirschman index and the fractionalization index are non-comparable because these values are explicitly dependent on the number of parties. However, in view of the normalization and decomposability feature, the comparison between the two situations is possible using the probability ratio index. The Herfindahl-Hirschman and the fractionalization indices are analyzed in greater details in Chakravarty (2015).

We use simple examples to demonstrate why probability ratio index has a comparative advantage over some of the other wellknown indices in terms of comparability. We start with the winning margin, defined as $m(s)=r_{1}(s)-r_{2}(s)$, often used as a measure of electoral competition (Mayhew, 1974). The higher the winning margin, the lower the extent of competition. For a two party election, the winning margin, goes hand in hand with the probability ratio index since one can show that $g_{N}^{*}(s)=1-\{m(s)\}^{2}$. However, the winning margin can be misleading in the case of multi-party political systems. Let $N=$ $\{1,2,3\}, s=(0.40,0.35,0.25)$ and $s^{\prime}=(0.39,0.34,0.27)$. Consider two elections $\overline{\mathcal{E}}^{1}=(N, s)$ and $\overline{\mathcal{E}}^{2}=\left(N, s^{\prime}\right)$. While the winning margin is the same in both elections, one can argue that competitiveness in $\overline{\mathcal{E}}^{2}$ is higher since votes are more evenly distributed. Our index gives the correct prediction because $g_{N}^{*}(s \prime)=0.99>0.98=g_{N}^{*}(s)$.

Now consider the LT-index that is defined as the inverse of the Herfindahl-Hirschman index (Laakso and Taagepera, 1979). We argue why the probability ratio index is better than LT-index $L T_{N}$ and the fractionalization index $\mathcal{F}_{N}(\mathbf{s} ; V)$. Consider two elections where the first is $\mathcal{E}^{1}=(\{1,2\}, s=(1 / 2,1 / 2))$ and the second is $\mathcal{E}^{2}=\left(\{1,2,3\}, s^{\prime}=(2 / 3,1 / 6,1 / 6)\right)$ and assume that in both these elections the total votes polled is 60 , that is, $V=60$. Observe that $L T_{N}(s)=L T_{N^{\prime}}\left(s^{\prime}\right)=2$ and $\mathcal{F}_{N}(s ; V)=\mathcal{F}_{N^{\prime}}\left(s^{\prime} ; V\right)=30 / 59$. Thus, according to both LT-index and the fractionalization index, elections $\mathcal{E}^{1}$ and $\mathcal{E}^{2}$ are equally competitive. This is clearly, unrealistic. Our measure shows that this is not the case. Specifically, $g_{N}^{*}(s)=1>g_{N^{\prime}}^{*}\left(s^{\prime}\right)=3 / 4$, that is, election $\mathcal{E}^{1}$ is more competitive than election $\mathcal{E}^{2}$, which is realistic. To see why the probability ratio index is a better measure than the entropy index $E_{N}$, consider two elections $\hat{\mathcal{E}}^{1}=(\{1,2\}, s=(1 / 2,1 / 2))$ and $\hat{\mathcal{E}}^{2}=\left(\{1,2,3\}, s^{\prime}=\left(x / 2, x / 2, s_{3}^{\prime}=1-x\right)\right)$, where $\quad x=0.23$. Then, $E_{N}(s)=E_{N^{\prime}}\left(s^{\prime}\right)=0.69$. Thus, according to the entropy index $E_{N}, \hat{\mathcal{E}}^{1}$ and $\hat{\mathcal{E}}^{2}$ are equally competitive, though the winner in $\hat{\mathcal{E}}^{2}$ gets $>77 \%$ of the total votes. Note that, in this case $g_{N}^{*}(s)=1>g_{N^{\prime}}^{*}\left(s^{\prime}\right)=0.57$, that is, the probability ratio index captures the extent of competition correctly. Finally, Endersby et al. (2002) proposed the product index as a measure of electoral competition which, for any set $N$ and any $s \in \Delta(N)$, is given by $C_{N}(s)=(|N|)^{|N|} \prod_{i \in N} s_{i}$. Note that higher value of $C_{N}$ indicates more intense competition. However, this measure cannot distinguish between situations where one or more candidates received zero votes. For example, consider two elections $\tilde{\mathcal{E}}^{1}=(\{1,2,3\}, s=$ $(1 / 2,1 / 2,0))$ and $\tilde{\mathcal{E}}^{2}=\left(\{1,2,3\}, s^{\prime}=(1,0,0)\right)$. Then, $C_{N}(s)=$ $C_{N^{\prime}}\left(s^{\prime}\right)=0$ implying unrealistically that $\tilde{\mathcal{E}}^{1}$ and $\tilde{\mathcal{E}}^{2}$ are equally competitive. However, $g_{N}^{*}(s)=3 / 4>g_{N}^{*}\left(s^{\prime}\right)=0$ and hence the probability ratio index does not suffer from such limitations.

\section{Why is comparability across elections important?}

Multi-party polities are present is several countries like Argentina, Austria, Belgium, Brazil, Canada, India, Indonesia, Israel, New Zealand, Taiwan, Tunisia, and Ukraine. More importantly, the number of candidates vary widely over time and across constituencies. For instance, the number of candidates in the Austrian presidential elections in 1992, 1998, 2004, and 2010 were 4, 5, 2, and 3, respectively. ${ }^{1}$ In the 2015 Canadian general elections the number of candidates varied from 3 to 10 with a mean of 5.30 and a standard deviation of 1.20. In contrast, the corresponding figures for the 2014 Indian general elections were 2, 42, 15.20, and 6.22. ${ }^{2}$ While it is true that some candidates in the multi-candidate elections are so-called "joke candidates", there are many multiparty polities even if we ignore such candidates. The U.K. general elections sees a few constituencies contested by the Official Monster Raving Loony Party whose candidates receive, at most, a few hundred votes. The U.K. is a genuine multi-party polity even if we discount such candidates. The variation in the number of candidates means that a competitiveness index must be able to compare elections with different number of candidates. However, the new index is satisfactorily applicable for comparison of competitiveness across elections. We can, therefore, employ our index for the said purpose using true data.

\section{Concluding comments}

We have analyzed the probability ratio index and argued why it is a good measure to compare competition across elections. The probability ratio index is simple to define and understand. It can also be used as a replacement for the fractionalization index of political heterogeneity since our measure is a normalized one.

The probability ratio index is affected by the introduction of small parties. To take an extreme example, suppose there are two parties with equal vote shares. In this case, the election is fully competitive. Suppose a third party enters the election. Assume that the new party receives no votes and the votes continue to be equally divided between the first two parties. While it might appear that the situation has not changed at all, the probability ratio index decreases to 0.75 implying that competitiveness has decreased! All indices, if examined closely, will throw up such instances. For instance, Flanigan and Zingale (1974) propose a competitiveness measure with regard to which they observe "We hope that our electoral indicator can be applied equally well to, at least, the Western democracies, even while recognizing that a measure, which is applicable to a broad range of situations usually becomes less appropriate for any specific one." We do not see this feature as a drawback and, on the contrary, we feel that this is an important feature of our index and captures the true essence of competition since it does not ignore the presence of parties receiving minimal vote shares in the election. Existence of such small parties is a movement away from a system representing equal vote shares; the case of maximum competition. Hence, it also increases the dominance of large parties.

A coalition of parties may be treated as a merger of vote shares of concerned parties and this is likely to reduce competition. Merger may take place via a sequence of transfers of vote shares of smaller parties to the largest party in the coalition. Another relevant issue here is that parties may form blocking coalition once some threshold is crossed. We leave these two issues as a future research program.

\section{Data Availability}

Data sharing not applicable to this article as nodatasets were generated or analyzed in detail during the current study.

Received: 8 January 2020; Accepted: 9 April 2020;

Published online: 13 May 2020

\section{Notes}

1 From: http://www.nsd.uib.no/european_election_database/country/austria/ presidential_elections.html

2 From: http://www.eci.nic.in/eci_main1/ElectionStatistics.aspx 


\section{References}

Acemoglu D, Robinson JA (2006) Economic origins of dictatorship and democracy. Cambridge University Press, Cambridge, United Kingdom

Afridi F, Dhillon A, Solan E (2019) Electoral competition and corruption: theory and evidence from India. Mimeo

Alfano MR, Baraldi AL (2015) Is there an optimal level of political competition in terms of economic growth? evidence from italy. Eur J Law Econ 39(2):263-285

Bardhan P, Yang T-T (June 2004) Political competition in economic perspective. Economics Department Working Paper No. E04-341, University of California, Berkeley

Besley T, Ghatak M (2005) Competition and incentives with motivated agents. Am Econ Rev 95(3):616-636

Besley T (2006) Principled agents? The political economy of good government. Oxford University Press, Oxford, United Kingdom

Bischoff CS (2006) Political competition and contestability: a study of the barriers to entry in 21 democracies. Unpublished doctoral dissertation, European University Institute, Florence

Boix C (1999) Setting the rules of the game: the choice of electoral systems in advanced democracies. Am Polit Sci Rev 93(3):609-624

Bourguignon F (1979) Decomposable income inequality measures. Econometrica 47(4):901-920

Capron H, Kruseman J-L (1988) Is political rivalry an incentive to vote? Public Choice 56:31-43

Chakravarty SR, Eichorn W (1991) An axiomatic characterization of a generalized index of concentration. J Prod Anal 2(2):103-112

Chakravarty SR, Weymark JA (1988) Axiomatization of the entropy numbers equivalent index of industrial concentration. In: Eichorn W (ed), Measurement in economics. Physica, Heidelberg

Chakravarty SR (2015) Inequality, polarization and conflict: an analytical study. Springer, New York

Chhibber P, Jensenius F, Suryanarayan P (2014) Party organization and party proliferation in india. Part Politics 20:489-505

Dahl RA (1971) Polyarchy: participation and opposition. Yale University Press, New Haven, New Jersey, USA

Dash BB, Mukherjee S (2015) Political competition and human development: evidence from the indian states. J Dev Stud 51:1-14

Duverger M (1964) Political parties: their organization and activity in the modern state. Wiley, New York, U.S.A

Endersby J, Galatas S, Rackaway C (2002) Closeness counts in canada: voter participation in the 1993 and 1997 federal elections. J Polit 64(2):610-631

Flanigan WH, Zingale NH (1974) Measures of electoral competition. Polit Methodol 1(4):31-60

Foster JE (1983) An axiomatic characterization of the theil measure of income inequality. J Econ Theory 31(1):105-121

Franklin MN (2004) Voter turnout and the dynamics of electoral competition in established democracies since 1945. Cambridge University Press, New York, U .S.A

Giebler H, Banducci S, Kritzinger S (2017) New perspectives on information and electoral competition. Acta Polit 52:429-435

Gini CW (1912) Variabilità e mutabilità: contributo allo studio delle distribuzioni e delle relazioni statistiche. C. Cuppini, Bologna

Herfindahl O (1950) Concentration in the U.S. steel industry. Unpublished doctoral dissertation, Columbia University

Hirschman AO (1964) The paternity of an index. Am Econ Rev 54:761

Hobolt SB, Klemmensen R (2008) Government responsiveness and political competition in comparative perspective. Comp Polit Stud 41(3):309-337

Jost L (2006) Entropy and diversity. Oikos 113:363-375

Kayser ME, Lindstädt R (2015) A cross-national measure of electoral competitiveness. Polit Anal 23:242-253

Kirchgassner G, Schimmelpfennig J (1992) Closeness counts if it matters for electoral victory: some empirical results for the united kingdom and the federal republic of germany. Public Choice 73:283-299
Kirchgassner G, Meyer zu Himmern A (1997) Expected closeness and turnout: an empirical analysis of the german general elections, 1983-1994. Public Choice 91(1):3-25

Laakso M, Taagepera R (1979) Effective number of parties: a measure with application to west europe. Comp Polit Stud 12:3-27

Lizzeri A, Persico N (2005) A drawback of electoral competition. J Eur Econ Assoc 3:1318-1348

Mayhew D (1974) Congressional elections: the case of the vanishing marginals Polity 6:295-317

Mitra A, Mitra S (2017) Electoral uncertainty, income inequality and the middle class. Econ J 127:1119-1152

Persson T, Torsten GR, Tabellini G (1997) Separation of powers and political accountability. Q J Econ 112(4):1163-1202

Powell GB (1982) Contemporary democracies: participation, stability and violence. Harvard University Press, Cambridge, Massachusetts, U.S.A.

Powell GB (2000) Elections as instruments of democracy: majoritarian and proportional visions. Yale University Press, New Haven, New Jersey, U.S.A.

Przeworski A, Limongi F (1993) Political regimes and economic growth. J Econ Perspect 7:51-69

Sen A (1974) Informational bases of alternative welfare approaches. J Public Econ 3:387-403

Simpson EH (1949) Measurement of diversity. Nature 163:688

Vanhanen T (1997) Prospects for democracy: a study of 172 countries. Routledge, New York, U.S.A.

Wright J (2008) Political competition and democratic stability in new democracies. Brit J Polit Sci 38(2):221-245

\section{Acknowledgements}

We are thankful to Arindam Paul for helping with the figures.

\section{Competing interests}

The authors declare no competing interests.

\section{Additional information}

Correspondence and requests for materials should be addressed to M.M.

Reprints and permission information is available at http://www.nature.com/reprints

Publisher's note Springer Nature remains neutral with regard to jurisdictional claims in published maps and institutional affiliations.

Open Access This article is licensed under a Creative Commons Attribution 4.0 International License, which permits use, sharing, adaptation, distribution and reproduction in any medium or format, as long as you give appropriate credit to the original author(s) and the source, provide a link to the Creative Commons license, and indicate if changes were made. The images or other third party material in this article are included in the article's Creative Commons license, unless indicated otherwise in a credit line to the material. If material is not included in the article's Creative Commons license and your intended use is not permitted by statutory regulation or exceeds the permitted use, you will need to obtain permission directly from the copyright holder. To view a copy of this license, visit http://creativecommons.org/ licenses/by/4.0/

(C) The Author(s) 2020 